\title{
Role of Glutathione in the Regulation of Cisplatin Resistance in Cancer Chemotherapy
}

\author{
Helen H. W. Chen' ${ }^{1}$ and Macus Tien Kuo \\ ${ }^{1}$ Department of Radiation Oncology, Institute of Clinical Medicine, Medical College and Hospital, National Cheng Kung University, \\ Tainan 70428, Taiwan \\ ${ }^{2}$ Department of Molecular Pathology, The University of Texas-MD Anderson Cancer Center, 7453 Fannin Boulevard, Houston, \\ TX 77054, USA
}

Correspondence should be addressed to Macus Tien Kuo, tkuo@mdanderson.org

Received 14 July 2010; Accepted 25 August 2010

Academic Editor: Zhe-Sheng Chen

Copyright (c) 2010 H. H. W. Chen and M. T. Kuo. This is an open access article distributed under the Creative Commons Attribution License, which permits unrestricted use, distribution, and reproduction in any medium, provided the original work is properly cited.

\begin{abstract}
Three mechanisms have been proposed for the role of glutathione (GSH) in regulating cisplatin (CDDP) sensitivities that affects its ultimate cell-killing ability: (i) GSH may serve as a cofactor in facilitating multidrug resistance protein 2- (MRP2-) mediated CDDP efflux in mammalian cells, since MRP2-transfected cells were shown to confer CDDP resistance; (ii) GSH may serve as a redox-regulating cytoprotector based on the observations that many CDDP-resistant cells overexpress GSH and $\gamma$ glutamylcysteine synthesis ( $\gamma$-GCS), the rate-limiting enzyme for GSH biosynthesis; (iii) GSH may function as a copper (Cu) chelator. Elevated GSH expression depletes the cellular bioavailable $\mathrm{Cu}$ pool, resulting in upregulation of the high-affinity $\mathrm{Cu}$ transporter (hCtr1) which is also a CDDP transporter. This has been demonstrated that overexpression of GSH by transfection with $\gamma$-GCS conferred sensitization to CDDP toxicity. This review describes how these three models were developed and critically reviews their importance to overall CDDP cytotoxicity in cancer cell treatments.
\end{abstract}

\section{Introduction}

Cisplatin (CDDP) has been the mainstay for the treatment of a broad spectrum of human malignancies since it was approved by the FDA about 30 years ago. It has been used in the first-line treatment modalities of human malignancies, including testicular [1], ovarian $[2,3]$, cervical [4], bladder [5], head and neck [6], and small cell lung cancers (SCLCs) $[3,7,8]$. However, many patients eventually relapse and develop resistance to the treatment. Once patients develop resistance to platinum $(\mathrm{Pt})$ drugs, other effective treatment options become limited. It is well known that CDDP acts on multiple cellular targets representing diverse signal transduction pathways. It is therefore conceivable that multiple mechanisms are involved in CDDP resistance, including reduction of drug transport and increased DNA adduct tolerance and repair $[9,10]$.

In this review, we focus on the role of glutathione (GSH) system in CDDP resistance. Three principal mechanisms are discussed here. The first mechanism involves the effects of GSH on the ATP-binding cassette (ABC) transportermediated CDDP transport; the second mechanism involves the redox-regulating capacity of GSH in detoxifying CDDP toxicity; the third mechanism involves regulation of the intracellular copper pool that affects CDDP uptake.

\section{Role of GSH in ABC Transporter-Mediated CDDP Transport}

The $\mathrm{ABC}$ transporters are a family of cytoplasmic membrane-spanned proteins that function as efflux pumps for eliminating antitumor agents, xenobiotics, and anionic lipophilic endogenous constituents [11-13]. Therefore, many of these transporters are also known as multidrug resistance proteins (MRPs). These transporters utilize ATP hydrolysis as energy source for substrate elimination [11]. Some transporters require GSH for substrate transport [11]. GSH may serve as substrate for conjugation reaction with 
CDDP prior to MRP-mediated transport. Ishikawa and Ali-Osman [14] first reported the formation of a $\mathrm{Pt}(\mathrm{GS})_{2}$ conjugate in L1210 leukemia cells. These investigators also reported that elimination of $\mathrm{Pt}(\mathrm{GS})_{2}$ across the membrane requires ATP, suggesting the involvement of an energy-dependent transporter of GSH-conjugate (termed GS-X pump) [15] in the elimination of $\mathrm{Pt}(\mathrm{GS})_{2}$ complex. Later, gene encoding MRP2, member $\mathrm{ABCC} 2$ in the $\mathrm{ABC}$ transporter family, was cloned; it was found that transfection of MRP2 into HEK-293 cells conferred CDDP resistance (10-fold) in the transfected cells [16]. MRP2-mediated efflux requires GSH [17]. These results demonstrated that MRP2 is the GS-X pump for the elimination of CDDP.

MRP2, like MRP1, can also transport GSSG itself, an oxidized form of GSH, with relatively higher affinity than does GSH $[18,19]$. Thus, these ABC transporters can be considered as regulators of intracellular GSSG-GSH homeostasis and the associated redox maintenance (see below). Many studies have demonstrated direct interactions between GSH and $A B C$ transporters $[20,21]$, suggesting that GSH may induce conformational changes that facilitate MRP-mediated substrate transport [11].

MRP2 is also known as a canalicular multispecific organic anion transporter (cMOAT) because of its high level of expression in the hepatic canalicular compartment and because it mediates the transport of a broad spectrum of nonbile salt organic anions from the liver into bile. cMOATdeficient (TR-) Wistar rats are mutated in the gene encoding MRP2, leading to defective hepatobiliary transport of a whole range of substrates, including bilirubin glucuronide.

MRP2 mRNA and protein levels can be markedly induced by treatments with metalloid salts including sodium arsenite $[\mathrm{As}(\mathrm{III})]$ and potassium antimonyl tartrate in primary rat and human hepatocytes [22]. Expression of MRP2 in primary rat hepatocytes is also induced by CDDP [23]. In one study, a single subcutaneous injection of CDDP $(5 \mathrm{mg} / \mathrm{kg})$ into Male Sprague-Dawley rats resulted in $>10$ fold induction of MRP2 in renal brush-border membranes within one day of treatment whereas nonsignificant induction of MRP2 levels was found in the livers [24]. In normal rats, $\sim 47 \%$ of the initial CDDP dose is excreted by the kidney whereas $1 \%-5 \%$ is excreted by the liver. The finding that increased expression of MRP2 in renal BBM upon injection of CDDP suggests that this transporter may be involved in the excretion of CDDP by the kidney. Since levels of MRP2 are already high in the hepatocytes, this may explain why only marginal increases of MRP2 was seen in the livers of CDDPtreated animals [24]. Moreover, a recent report showed that elevated MRP2 levels seemed to affect the efficacy of CDDPbased chemotherapy in hepatocellular carcinoma HCC [25].

While Ishikawa and Ali-Osman [14] initially reported that formation of $\mathrm{Pt}(\mathrm{GS})_{2}$ complex reached a maximal level after $12 \mathrm{hrs}$ in L1210 cells treated with $20 \mu \mathrm{M}$ CDDP, corresponding to $\sim 60 \%$ of the intracellular Pt content, however, Berners-Price and Kuchel studied the reaction of CDDP with GSH inside intact red blood cells using ${ }^{1} \mathrm{H}$ spin-echo nuclear magnetic resonance (NMR) and detected no formation of Pt-GSH bonds within $4 \mathrm{hrs}$ of incubation [26]. Recently, Kasherman et al. [27] studied the interactions of CDDP with cell extracts prepared from ovarian cancer cells and found very little $\mathrm{Pt}(\mathrm{GS})_{2}$ by the $\left[{ }^{1} \mathrm{H},{ }^{15} \mathrm{~N}\right] \mathrm{HSQC}$ approach. Since CDDP can bind to many thiol-containing proteins and its primary cytotoxic target DNA, once inside the cells, these cellular constituents will compete against GSH for CDDP binding. These investigators found that the majority of glutathionated complexes were in fact in high molecular mass fraction (whereas the molecular mass of $\mathrm{Pt}(\mathrm{GS})_{2}$ is 809). Therefore, the significance of GSH-CDDP binding as an important step for CDDP elimination remains somewhat controversial.

\section{Role of the GSH System as a Cytoprotector in CDDP Resistance}

GSH is an abundant thiol-containing tri-peptide (GluCys-Gly), constituting $1 \sim 10 \mathrm{mM}$ in mammalian cells. De novo biosynthesis of GSH is controlled by the rate-limiting enzyme, glutamate-cysteine ligase (GCL, also known as $\gamma$ glutamylcysteine synthetase, $\gamma$-GCS) which consists of a catalytic (heavy) ( $\gamma$-GCSh) and a regulatory (light) subunit ( $\gamma$-GCSI). $\gamma$-GCS carries out the initial ligating reaction of glutamine (Glu) and cysteine (Cys). Production of GSH is accomplished by the subsequent reaction involving glycine (Gly) by GSH synthetase (Figure 1). GSH can be oxidized into GSSG by GSH peroxidase using $\mathrm{H}_{2} \mathrm{O}_{2}$ as a substrate whereas GSSG can be reduced back to GSH by GSSG reductase using NADPH as a cofactor. Therefore, GSHGSSG system provides an important redox buffer in living organisms.

As alluded to earlier, the transport activity of MRP2 (and other members of the MRP family) is regulated by GSH availability. Since $\gamma$-GCS is the rate-limiting enzyme for the biosynthesis of GSH, coregulation of $\gamma$-GCS and MRPs would facilitate the efflux activity (Figure 1). Indeed, we found that a number of cytotoxic agents can simultaneously induce the expression of both $\gamma$-GCSh and MRP, including CDDP [28], carcinogens [29], and prooxidants [30, 31]. Furthermore, enhanced expression of $\gamma$-GCSh/MRP1 was found in colorectal cancers, which are associated with inflammation-associated oxidative stress $[32,33]$. These observations, taken together, strongly suggest that GSH $/ \gamma$ GCS system is a molecular sensor of oxidative stress conditions [11].

\subsection{Frequent Upregulation of GSH and $\gamma$-GCS in CDDP-} Resistant Variants. Previous studies have reported that exposure of cultured cells to CDDP led to the development of CDDP resistance which was correlated with increased cellular GSH levels [34-39]. Moreover, GSH depletion by buthionine-sulfoximine (BSO) has been associated with increased sensitivity to CDDP $[8,14-17]$. In many cases, when $\gamma$-GCS mRNA contents were measured, elevated levels of $\gamma$-GCSh mRNA were also correlated with CDDP resistance. These studies have been widely taken as that intracellular GSH levels play an important role in regulating CDDP resistance [34, 40-43], perhaps through a GSHmediated cytoprotective mechanism. However, molecular 
mechanisms as how GSH functions as a cytoprotector for CDDP resistance have not been elucidated.

However, this proposition has several caveats. One, these studies frequently used CDDP-treated cells and the observations were mostly correlative in nature. Whether elevated expression of GSH indeed is causally responsible for the CDDP resistance needs to be critically evaluated. Two, as alluded to above, induction of $\gamma$-GCS, and thus GSH, in CDDP-treated cells may be an oxidative stress-induced phenomenon because $\gamma$-GCS/GSH is a sensor/regulator of reactive oxygen species (ROSs) imbalance, and its expression can be induced by a wide array of cytotoxic insults. In many cases, elevated expression of $\gamma$-GCS/GSH under cytotoxic insult did not confer CDDP resistance in the treated cells [44]. Three, also as alluded above, normal cells usually contain millimolar levels of GSH. Stoichiometrically, these abundant amounts of thiol compound may already be sufficient to neutralize the cytotoxic effects of CDDP which are usually in micromolar ranges. Thus, increased GSH content found in most of CDDP-treated cells may not necessarily have a major impact in the detoxification mechanism of CDDP. As will be described below, we found that elevated expression GSH per se induces cellular sensitization to CDDP treatment [45].

\subsection{Mechanisms of Upregulation of $\gamma-G C S / G S H$ by Oxidative} Stress. Both transcriptional regulation and posttranscriptional regulation have been reported for the upregulation of $\gamma$-GCSh by various cytotoxic assaults. Transcriptional regulation is mediated by an antioxidant response element (ARE, $5^{\prime}$-TGAGTCA) located at the promoter of the $\gamma$-GCSh allele, which interacts with the NF-E2-related transcription factor (Nrf2). Under unstressed conditions, majority of Nrf2 is in the cytosol and bound to Kelch-like ECH-associated protein (Keap1) which functions as a substrate adaptor for a Cullindependent E2 ubiquitin ligase complex and targets Nrf2 for ubiquitination and proteasomal degradation. Because Keap1 is a redox-sensitive E3 ligase, oxidative stress conditions induce Keap1 sulfhydryl group modification and conformational changes, resulting in Nrf2 release from proteasomal degradation and allowing it to translocate to the nucleus [46]. By heterodimerizing with the small Maf protein as coactivator, together, they bind to the ARE and transactivate $\gamma$-GCSh expression. Expression of MRP2 is also apparently regulated by Nrf2 signal. Livers from hepatocyte-specific Gclc/ $\gamma$-GCSh-knockout mice showed elevated expression of Nrf2 and MRP2 due to elevated oxidative stress [47].

Regulation of $\gamma$-GCSh by oxidative stress is also controlled by posttranscriptional signal. We demonstrated that oxidative stress induces $\gamma$-GCSh mRNA stabilization through the p38 MAP kinase pathways. Under oxidative stress conditions, P38 MAP kinase activates MAPKAPK2, which promotes translocation of mRNA-stabilizing factor HuR from the nucleus to the cytoplasmic compartment, where it stabilizes $\gamma$-GCSh mRNA by binding to the AU-rich motif located at the $3^{\prime}$ untranslated region. The accumulated $\gamma$ GCSh mRNA produces elevated levels of GSH that feed back to suppress $\gamma$-GCSh mRNA stabilization [44] and the Nrf2 signal-mediated $\gamma$-GCSh transcription as mentioned above.

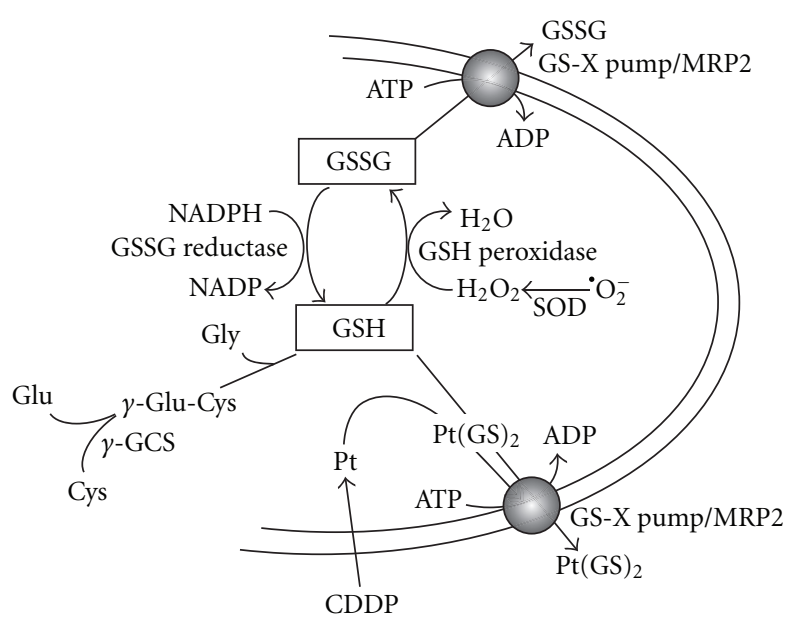

FIGURE 1: The role of GSH in MRP-mediated CDDP transport. De novo biosynthesis of GSH is carried out by $\gamma$-GCS, which conjugates glutamine (Glu) and cysteine (Cys) followed by GSH synthetase using glycine (Gly) as a substrate. GSH can be oxidized into GSSG by GSH peroxidase. SOD refers to superoxide dismutase. GSSG can be reduced to GSH by GSSG reductase. GSSG is a substrate of the MRP/GS-X pump whereas GSH functions as a cofactor for MRPmediated CDDP transport.

\section{Role of GSH in Human High-Affinity Cu Transporter- (hCtr1-) Mediated CDDP Transport}

In 1998, while we were studying the coregulation of $\gamma$ GCSh and MRP1 by CDDP, we found that transfection of recombinant DNA encoding the $\gamma$-GCSh subunit alone was sufficient to enhance GSH levels in the transfected cells [29]. Surprisingly, we also found that these stable $\gamma$ GCSh-transfected cells exhibited hypersensitivity instead of resistance to the toxicity of CDDP. Hypersensitivity to the toxic effect of CDDP was associated with enhanced uptake of CDDP in these transfected cells. However, transporter for the uptake of CDDP was not available at the time. CDDP transporter was later identified as the high-affinity $\mathrm{Cu}$ transporter (hCtr1) [48] and the mechanism of this hypersensitization was due to the upregulation of hCtr1 in these transfected cells [45] (see below).

4.1. Identification of hCtr1 as CDDP Transporter. Transporter for CDDP was identified using a genetic screening approach. Ishida et al. [48] mutagenized yeast cells with a transpose library after selecting mutants that were able to grow in the presence of a toxic dose of CDDP. One of the mutants was defective in the Macl gene which encodes a copper concentration-dependent transcription factor for the expression of several genes involved in the uptake of iron and copper [49]. These investigators subsequently determined that yCtrl is the target gene that could recapitulate the CDDP-resistance phenotype observed in the mac1s mutant. Likewise, murine embryonic fibroblasts derived from $m C \operatorname{tr} 1(-/-)$ animals exhibited reduced CDDP 
accumulation as compared with their respective wild-type counterparts.

The discovery that Ctr1 is involved in Pt drug transport underscores the important role of $\mathrm{Cu}$ metabolism in the efficacy of Pt drug chemotherapy. Copper is an essential micronutrient for cell survival, yet $\mathrm{Cu}$ overload is toxic. To meet their need for $\mathrm{Cu}$ while avoiding toxicity, all living organisms from yeast to humans have developed an evolutionarily conserved system to regulate $\mathrm{Cu}$ homeostasis. This system consists of a transporter ( $\mathrm{Ctr} 1$ ) for $\mathrm{Cu}$ acquisition, chaperones (HAH1, COX17, and CCS) for Cu delivery to various intracellular compartments, and exporters (ATP7A and ATP7B) for $\mathrm{Cu}$ elimination (Figure 2). Although $\mathrm{Cu}$ entry can also be carried out by divalent metal transporter 1 (DMT1), which transports a broad range of divalent metal ions including $\mathrm{Cu}(\mathrm{II})$, the majority of $\mathrm{Cu}$ acquisition is accomplished by $\mathrm{Ctr} 1$, which transports $\mathrm{Cu}(\mathrm{I})$. The Belgrade rat, which has a mutation in $d m t 1$, has no $\mathrm{Cu}$-deficient phenotype [50]. Extracellular $\mathrm{Cu}$ exists in the oxidized form $[\mathrm{Cu}(\mathrm{II})]$ which is converted into $\mathrm{Cu}(\mathrm{I})$ by membranebound cupric reductases, relevant to the yeast Fre1 and Fre2 reductases [51, 52], for hCtr1-mediated transport.

Ctr1 plays an important role in the regulation of intracellular $\mathrm{Cu}$ homeostasis. This was first demonstrated in yeast. Expression of yeast Ctr ( $y$ Ctrl and $y C t r 3)$ is transcriptionally upregulated under $\mathrm{Cu}$-deplete conditions and is downregulated under $\mathrm{Cu}$-replete conditions. During $\mathrm{Cu}-$ depleted conditions, the transcription factor Maclp binds to the metal binding sequence $\left[5^{\prime}-\mathrm{TTTGC}(\mathrm{T} / \mathrm{G}) \mathrm{C}(\mathrm{A} / \mathrm{G})\right]$ located at the promoters of $y C \operatorname{Ctr} 1$ and $y C t r 3$ [53-55] and turns on the expression of these genes. Under $\mathrm{Cu}$ replete conditions, Mac1 dissociates from the promoters, resulting in shut-down of the expression of $y C t r 1$ and $y C t r 3$. In the meantime, the transcription factor Acel is activated to induce the expression of genes encoding $\mathrm{Cu}$ chelating proteins (Cup1 and Crs5) and the antioxidant superoxide dismutase (SOD1) [56-58] to protect cells from $\mathrm{Cu}$ overload. Both Mac1 and Acel contain zinc finger (ZF) motifs that function as metallosensors. A transcriptional regulation mechanism is also involved in $\mathrm{Cu}(\mathrm{I})$-dependent regulation of the Drosophila CtrB gene [59], a homologue of $y C t r 1$ and $y C t r 3$. In addition to transcriptional regulation, posttranslational regulation has been reported for $y \mathrm{Ctr} 1$ and yCtr3 proteins in response to $\mathrm{Cu}$ stress [60].

Available information in the literature regarding the mechanisms of regulation of human copper transporter (hCtr1) is controversial. It has been reported that regulation of mammalian Ctr1 is controlled at the posttranslational levels. Elevated $\mathrm{Cu}$ levels induce the trafficking of hCtr1 from the plasma membrane to endosomal/lysosomal compartments where Ctr1 is degraded $[61,62]$.

We investigated the regulation of hCtrl expression in response to $\mathrm{Cu}$ concentration stress and found that levels of hCtr1 mRNA were decreased in cultured small cell lung cancer (SCLC) cells treated with $\mathrm{CuSO}_{4}$ but were increased in cells treated with the $\mathrm{Cu}$-depleting agent bathocuproine disulfonic acid. We further demonstrated that the ZF transcription factor Sp1 plays an important role in the transcriptional regulation of hCtr1 [63]. These results, taken

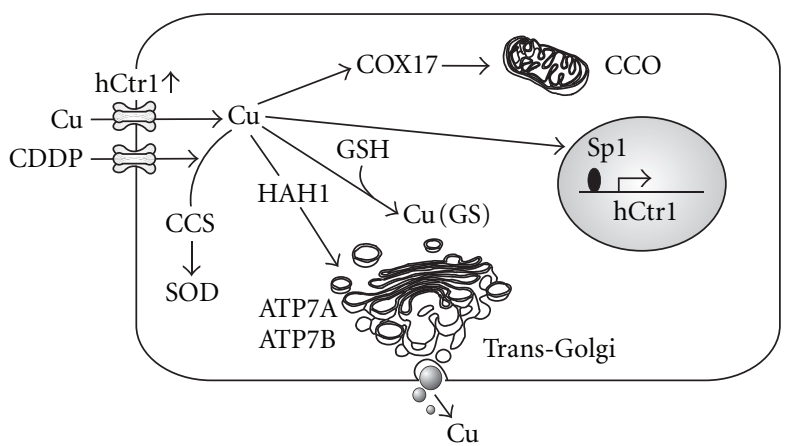

FIGURE 2: The effects of $\gamma$-GCSh overexpression on cellular $\mathrm{Cu}$ metabolism and CDDP transport. Overexpression of $\gamma$-GCSh, which catalyzes the ligation of cysteine (Cys) and glutamate (Glu), results in increased GSH levels. Excess GSH functions as a $\mathrm{Cu}$ depletor, as evidenced by the reduction in CCO and SOD activity, and holo-ceruloplasmin $(\mathrm{Cu}-\mathrm{Cpm})$ contents. Intracellular $\mathrm{Cu}$ deficiency upregulates hCtr1 expression, which is regulated by transcription factor, Spl. Upregulation of hCtrl enhances CDDP uptake, resulting in elevated sensitivities to CDDP treatment. CCS, $\mathrm{HAH} 1$, and COX17 are $\mathrm{Cu}$ chaperones that shuffle $\mathrm{Cu}$ to their respective targets as indicated by arrows.

together, indicate that expression of hCtr1 is upregulated under copper deplete condition but is downregulated under copper replete conditions.

4.2. Mechanism of Sensitization of GSH-Overproducing Cells to CDDP Treatment. The findings that hCtrl expression is regulated by intracellular $\mathrm{Cu}$ bioavailability prompted us to investigate whether sensitization of GSH-overproducing cells in the $\gamma$-GCSh-transfected cells to CDDP was due to reduced intracellular bioavailable $\mathrm{Cu}$ contents, resulting in upregulation of hCtrl expression. It has been well established that $\mathrm{Cu}$ can form a Cu-GSH complex by directly interacting with its internal cysteine-SH residue of GSH. However, unlike formation of $\mathrm{Pt}(\mathrm{GS})_{2}$, formation of $\mathrm{Cu}(\mathrm{GS})$ is almost a spontaneous reaction and requires no enzymatic involvement [63-65], resulting in reduced intracellular bioavailability of $\mathrm{Cu}$ levels. We found that the $\gamma$-GCShtransfected cells indeed showed $\mathrm{Cu}$ deficiency as evidenced by the reduced enzymatic activities of $\mathrm{Cu}, \mathrm{Zn}$ superoxide dismutase (SOD1) and mitochondrial cytochrome $\mathrm{C}$ oxidase (CCO) as compared with those in the nontransfected cells [45]. Moreover, reduction of $\mathrm{Cu}$ content in ceruloplasmin, a copper-containing ferroxidase that plays an important role in mammalian iron homeostasis, was also found in the transfected cells. These enzymatic markers have been used as biochemical signature for intracellular $\mathrm{Cu}$ bioavailability [66]. Levels of hCtr1 expression in the three independently established $\gamma$-GCSh-transfected cells were 3 - to 4fold increases as compared with that in the parental cells. No substantial decreases in ATP7A or ATP7B levels were observed. Moreover, increased hCtrl expression in these $\gamma$ $G C S h$-transfected cells was associated with enhanced CDDP uptake [45]. 
Sensitization of $\gamma$-GCSh-transfected cells to CDDP could be reversed when these cells were treated with GSHdepleting agent buthionine-sulfoximine (BSO). This reversal was associated with the reduced expression of hCtr1 due to the reinstated $\mathrm{Cu}$ bioavailability in the transfected cells as analyzed by activities of the $\mathrm{Cu}$ signature enzymes [45].

Taken together, our finding demonstrated that elevated levels of GSH per se can sensitize CDDP toxicity. The elucidation that GSH functions as a $\mathrm{Cu}$ chelator in upregulating its transporter hCtrl has important implications in cancer chemotherapy using platinum-based antitumor agents. We note that recent report has shown that another copper chelator, tetrathiomolybdate, can enhance CDDP sensitivity in ovarian cancer animal model [67].

\section{Conclusion and Future Prospective}

The three major mechanisms that control CDDP sensitivity by GSH described in the paper reflect the complexity of a small peptide that can regulate the efficacy of CDDP toxicity. The significance of each of these mechanisms may depend upon various cell types and/or different cell physiologic conditions. As alluded to above, CDDP can interact with many cellular targets and affect many signal transduction pathways to elicit its cytotoxicity. Likewise, GSH is an important redox regulator and redox signaling can affect many important cellular processes [11]. Thus, GSH may have far-reaching effects on CDDP sensitivity. Future investigations are needed to address the roles of GSH in the global effects of CDDP sensitivity.

\section{Acknowledgments}

This research was supported in part by Grants NSC972314-B-006-043 from the National Science Council, Taiwan, NCKU-9701014 from National Cheng Kung University (to H. H. W. Chen), and R01-CA79085 (M. T. Kuo) and CA016672 (MD Anderson Cancer Support Grant) from the National Cancer Institute.

\section{References}

[1] S. A. Hussain, Y. T. Ma, and M. H. Cullen, "Management of metastatic germ cell tumors," Expert Review of Anticancer Therapy, vol. 8, no. 5, pp. 771-784, 2008.

[2] M. Markman, "Antineoplastic agents in the management of ovarian cancer: current status and emerging therapeutic strategies," Trends in Pharmacological Sciences, vol. 29, no. 10, pp. 515-519, 2008.

[3] F. Muggia, "Platinum compounds 30 years after the introduction of cisplatin: implications for the treatment of ovarian cancer," Gynecologic Oncology, vol. 112, no. 1, pp. 275-281, 2009.

[4] D. H. Moore, C. Tian, B. J. Monk, H. J. Long, G. A. Omura, and J. D. Bloss, "Prognostic factors for response to cisplatin-based chemotherapy in advanced cervical carcinoma: a Gynecologic Oncology Group Study," Gynecologic Oncology, vol. 116, no. 1, pp. 44-49, 2010.
[5] D. J. Gallagher and M. I. Milowsky, "Bladder cancer," Current Treatment Options in Oncology, vol. 10, no. 3-4, pp. 205-215, 2009.

[6] E. S. Yang, B. M. Murphy, C. H. Chung et al., "Evolution of clinical trials in head and neck cancer," Critical Reviews in Oncology/Hematology, vol. 71, no. 1, pp. 29-42, 2009.

[7] L. Kelland, "The resurgence of platinum-based cancer chemotherapy," Nature Reviews Cancer, vol. 7, no. 8, pp. 573584, 2007.

[8] M. B. Lustberg and M. J. Edelman, "Optimal duration of chemotherapy in advanced non-small cell lung cancer," Current Treatment Options in Oncology, vol. 8, no. 1, pp. 3846, 2007.

[9] Z. H. Siddik, "Cisplatin: mode of cytotoxic action and molecular basis of resistance," Oncogene, vol. 22, no. 47, pp. 7265-7279, 2003.

[10] D. Wang and S. J. Lippard, "Cellular processing of platinum anticancer drugs," Nature Reviews Drug Discovery, vol. 4, no. 4, pp. 307-320, 2005.

[11] M. T. Kuo, "Redox regulation of multidrug resistance in cancer chemotherapy: molecular mechanisms and therapeutic opportunities," Antioxidants and Redox Signaling, vol. 11, no. 1, pp. 99-133, 2009.

[12] G. Szakács, J. K. Paterson, J. A. Ludwig, C. Booth-Genthe, and M. M. Gottesman, "Targeting multidrug resistance in cancer," Nature Reviews Drug Discovery, vol. 5, no. 3, pp. 219-234, 2006.

[13] P. Borst and R. Oude Elferink, "Mammalian ABC transporters in health and disease," Annual Review of Biochemistry, vol. 71, pp. 537-592, 2002.

[14] T. Ishikawa and F. Ali-Osman, "Glutathione-associated cis-diamminedichloroplatinum(II) metabolism and ATPdependent efflux from leukemia cells. Molecular characterization of glutathione-platinum complex and its biological significance," Journal of Biological Chemistry, vol. 268, no. 27, pp. 20116-20125, 1993.

[15] T. Ishikawa, C. D. Wright, and H. Ishizuka, "GS$\mathrm{X}$ pump is functionally overexpressed in cisdiamminedichloroplatinum(II)-resistant human leukemia HL-60 cells and down- regulated by cell differentiation," Journal of Biological Chemistry, vol. 269, no. 46, pp. 2908529093, 1994.

[16] Y. Cui, J. König, U. Buchholz, H. Spring, I. Leier, and D. Keppler, "Drug resistance and ATP-dependent conjugate transport mediated by the apical multidrug resistance protein, MRP2, permanently expressed in human and canine cells," Molecular Pharmacology, vol. 55, no. 5, pp. 929-937, 1999.

[17] C. C. Paulusma, M. A. van Geer, R. Evers et al., "Canalicular multispecific organic anion transporter/multidrug resistance protein 2 mediates low-affinity transport of reduced glutathione," Biochemical Journal, vol. 338, no. 2, pp. 393-401, 1999.

[18] D. W. Loe, K. C. Almquist, R. G. Deeley, and S. P. C. Cole, "Multidrug resistance protein (MRP)-mediated transport of leukotriene C4 and chemotherapeutic agents in membrane vesicles: demonstration of glutathione-dependent vincristine transport," Journal of Biological Chemistry, vol. 271, no. 16, pp. 9675-9682, 1996.

[19] G. J. R. Zaman, J. Lankelma, O. van Tellingen et al., "Role of glutathione in the export of compounds from cells by the multidrug-resistance-associated protein," Proceedings of the National Academy of Sciences of the United States of America, vol. 92, no. 17, pp. 7690-7694, 1995. 
[20] E. M. Leslie, K.-I. Ito, P. Upadhyaya, S. S. Hecht, R. G. Deeley, and S. P. C. Cole, "Transport of the $\beta$-O-glucuronide conjugate of the tobacco-specific carcinogen 4-(methylnitrosamino)-1(3-pyridyl)-1-butanol (NNAL) by the multidrug resistance protein 1 (MRP1): requirement for glutathione or a nonsulfur-containing analog," Journal of Biological Chemistry, vol. 276, no. 30, pp. 27846-27854, 2001.

[21] Y.-M. Qian, C. E. Grant, C. J. Westlake et al., "Photolabeling of human and murine multidrug resistance protein 1 with the high affinity inhibitor [125I]LY475776 and azidophenacyl[35S] glutathione," Journal of Biological Chemistry, vol. 277, no. 38, pp. 35225-35231, 2002.

[22] L. Vernhet, M.-P. Séité, N. Allain, A. Guillouzo, and O. Fardel, "Arsenic induces expression of the multidrug resistance associated protein 2 (MRP2) gene in primary rat and human hepatocytes," Journal of Pharmacology and Experimental Therapeutics, vol. 298, no. 1, pp. 234-239, 2001.

[23] H.-M. Kauffmann, D. Keppler, J. Kartenbeck, and D. Schrenk, "Induction of cMrp/cMoat gene expression by cisplatin, 2acetylaminofluorene, or cycloheximide in rat hepatocytes," Hepatology, vol. 26, no. 4, pp. 980-985, 1997.

[24] M. Demeule, M. Brossard, and R. Béliveau, "Cisplatin induces renal expression of P-glycoprorein and canalicular multispecific organic anion transporter," American Journal of Physiology—Renal Physiology, vol. 277, no. 6, part 2, pp. F832F840, 1999.

[25] P. V. Korita, T. Wakai, Y. Shirai, et al., "Multidrug resistanceassociated protein 2 determines the efficacy of cisplatin in patients with hepatocellular carcinoma," Oncology Reports, vol. 23, no. 4, pp. 965-972, 2010.

[26] S. J. Berners-Price and P. W. Kuchel, "Reaction of cis- and trans-[PtCl2(NH3)2] with reduced glutathione inside human red blood cells, studied by $1 \mathrm{H}$ and $15 \mathrm{~N}-1 \mathrm{H}$ dept NMR," Journal of Inorganic Biochemistry, vol. 38, no. 4, pp. 327-345, 1990.

[27] Y. Kasherman, S. Sturup, and D. Gibson, "Is glutathione the major cellular target of cisplatin? A study of the interactions of cisplatin with cancer cell extracts," Journal of Medicinal Chemistry, vol. 52, no. 14, pp. 4319-4328, 2009.

[28] T. Ishikawa, J.-J. Bao, Y. Yamane et al., "Coordinated induction of MRP/GS-X pump and $\gamma$-glutamylcysteine synthetase by heavy metals in human leukemia cells," Journal of Biological Chemistry, vol. 271, no. 25, pp. 14981-14988, 1996.

[29] Y. Yamane, M. Furuichi, R. Song et al., "Expression of multidrug resistance protein/GS-X pump and $\gamma$-glutamylcysteine synthetase genes is regulated by oxidative stress," Journal of Biological Chemistry, vol. 273, no. 47, pp. 31075-31085, 1998.

[30] Y. Ikegami, S. Tatebe, Y. C. Lin-Lee, Q. W. Xie, T. Ishikawa, and M. T. Kuo, "Induction of MRP1 and gamma-glutamylcysteine synthetase gene expression by interleukin lbeta is mediated by nitric oxide-related signalings in human colorectal cancer cells," Journal of Cellular Physiology, vol. 185, no. 2, pp. 293301, 2000.

[31] Y.-C. Lin-Lee, S. Tatebe, N. Savaraj, T. Ishikawa, and M. Tien Kuo, "Differential sensitivities of the MRP gene family and $\gamma$-glutamylcysteine synthetase to prooxidants in human colorectal carcinoma cell lines with different p53 status," Biochemical Pharmacology, vol. 61, no. 5, pp. 555-563, 2001.

[32] M. T. Kuo, J.-J. Bao, S. A. Curley, M. Ikeguchi, D. A. Johnston, and T. Ishikawa, "Frequent coordinated overexpression of the MRP/GS-X pump and $\gamma$-glutamylcysteine synthetase genes in human colorectal cancers," Cancer Research, vol. 56, no. 16, pp. 3642-3644, 1996.
[33] S. Tatebe, H. Unate, F. A. Sinicrope, et al., "Expression of heavy subunit of $\gamma$-glutamylcysteine synthetase ( $\gamma$-GCSh) in human colorectal carcinoma," International Journal of Cancer, vol. 97, no. 1, pp. 21-27, 2002.

[34] A. K. Godwin, A. Meister, P. J. O’Dwyer, C. S. Huang, T. C. Hamilton, and M. E. Anderson, "High resistance to cisplatin in human ovarian cancer cell lines is associated with marked increase of glutathione synthesis," Proceedings of the National Academy of Sciences of the United States of America, vol. 89, no. 7, pp. 3070-3074, 1992.

[35] C. Meijer, N. H. Mulder, H. Timmer-Bosscha, W. J. Sluiter, G. J. Meersma, and E. G. E. de Vries, "Relationship of cellular glutathione to the cytotoxicity and resistance of seven platinum compounds," Cancer Research, vol. 52, no. 24, pp. 6885-6889, 1992.

[36] C. P. Schröder, A. K. Godwin, P. J. O’Dwyer, K. D. Tew, T. C. Hamilton, and R. F. Ozols, "Glutathione and drug resistance," Cancer Investigation, vol. 14, no. 2, pp. 158-168, 1996.

[37] K. Mishima, A. Baba, M. Matsuo, Y. Itoh, and R. Oishi, "Protective effect of cyclic AMP against cisplatin-induced nephrotoxicity," Free Radical Biology and Medicine, vol. 40, no. 9, pp. 1564-1577, 2006.

[38] T. Sasada, H. Nakamura, S. Ueda et al., "Secretion of thioredoxin enhances cellular resistance to cisdiamminedichloroplatinum (II)," Antioxidants and Redox Signaling, vol. 2, no. 4, pp. 695-705, 2000.

[39] B. A. J. Jansen, J. Brouwer, and J. Reedijk, "Glutathione induces cellular resistance against cationic dinuclear platinum anticancer drugs," Journal of Inorganic Biochemistry, vol. 89, no. 3-4, pp. 197-202, 2002.

[40] G. V. Z. Dedoussis and N. K. Andrikopoulos, "Glutathione depletion restores the susceptibility of cisplatin-resistant chronic myelogenous leukemia cell lines to Natural Killer cell-mediated cell death via necrosis rather than apoptosis," European Journal of Cell Biology, vol. 80, no. 9, pp. 608-614, 2001.

[41] A. Troyano, C. Fernández, P. Sancho, E. De Blas, and P. Aller, "Effect of glutathione depletion on antitumor drug toxicity (Apoptosis and Necrosis) in U-937 human promonocytic cells: the role of intracellular oxidation," Journal of Biological Chemistry, vol. 276, no. 50, pp. 47107-47115, 2001.

[42] K.-S. Yao, A. K. Godwin, S. W. Johnson, R. F. Ozols, P. J. O'Dwyer, and T. C. Hamilton, "Evidence for altered regulation of $\gamma$-glutamylcysteine synthetase gene expression among cisplatin-sensitive and cisplatin-resistant human ovarian cancer cell lines," Cancer Research, vol. 55, no. 19, pp. 4367-4374, 1995.

[43] K. Ikeda, K. Miura, S. Himeno, N. Imura, and A. Naganuma, "Glutathione content is correlated with the sensitivity of lines of PC12 cells to cisplatin without a corresponding change in the accumulation of platinum," Molecular and Cellular Biochemistry, vol. 219, no. 1-2, pp. 51-56, 2001.

[44] I.-S. Song, S. Tatebe, W. Dai, and M. T. Kuo, "Delayed mechanism for induction of $\gamma$-glutamylcysteine synthetase heavy subunit mRNA stability by oxidative stress involving p38 mitogen-activated protein kinase signaling," Journal of Biological Chemistry, vol. 280, no. 31, pp. 28230-28240, 2005.

[45] H. H. W. Chen, I.-S. Song, A. Hossain et al., "Elevated glutathione levels confer cellular sensitization to cisplatin toxicity by up-regulation of copper transporter hCtr1," Molecular Pharmacology, vol. 74, no. 3, pp. 697-704, 2008.

[46] D. D. Zhang and M. Hannink, "Distinct cysteine residues in Keap1 are required for Keap1-dependent ubiquitination of 
Nrf2 and for stabilization of Nrf2 by chemopreventive agents and oxidative stress," Molecular and Cellular Biology, vol. 23, no. 22, pp. 8137-8151, 2003.

[47] J. M. Maher, M. Z. Dieter, L. M. Aleksunes et al., "Oxidative and electrophilic stress induces multidrug resistanceassociated protein transporters via the nuclear factor-E2related factor-2 transcriptional pathway," Hepatology, vol. 46, no. 5, pp. 1597-1610, 2007.

[48] S. Ishida, J. Lee, D. J. Thiele, and I. Herskowitz, "Uptake of the anticancer drug cisplatin mediated by the copper transporter Ctr1 in yeast and mammals," Proceedings of the National Academy of Sciences of the United States of America, vol. 99, no. 22, pp. 14298-14302, 2002.

[49] J. Jungmann, H.-A. Reins, J. Lee et al., "MAC1, a nuclear regulatory protein related to $\mathrm{Cu}$-dependent transcription factors is involved in $\mathrm{Cu} / \mathrm{Fe}$ utilization and stress resistance in yeast," EMBO Journal, vol. 12, no. 13, pp. 5051-5056, 1993.

[50] M. D. Garrick, K. G. Dolan, C. Horbinski et al., "DMT1: a mammalian transporter for multiple metals," BioMetals, vol. 16, no. 1, pp. 41-54, 2003.

[51] E. Georgatsou, L. A. Mavrogiannis, G. S. Fragiadakis, and D. Alexandraki, "The yeast Fre1p/Fre2p cupric reductases facilitate copper uptake and are regulated by the coppermodulated Maclp activator," Journal of Biological Chemistry, vol. 272, no. 21, pp. 13786-13792, 1997.

[52] R. Hassett, D. R. Dix, D. J. Eide, and D. J. Kosman, "The Fe(II) permease Fet4p functions as a low affinity copper transporter and supports normal copper trafficking in Saccharomyces cerevisiae," Biochemical Journal, vol. 351, no. 2, pp. 477-484, 2000.

[53] L. T. Jensen, M. C. Posewitz, C. Srinivasan, and D. R. Winge, "Mapping of the DNA binding domain of the copperresponsive transcription factor Macl from Saccharomyces cerevisiae," Journal of Biological Chemistry, vol. 273, no. 37, pp. 23805-23811, 1998.

[54] S. Labbé, Z. Zhu, and D. J. Thiele, “Copper-specific transcriptional repression of yeast genes encoding critical components in the copper transport pathway," Journal of Biological Chemistry, vol. 272, no. 25, pp. 15951-15958, 1997.

[55] Y. Yamaguchi-Iwai, M. Serpe, D. Haile et al., "Homeostatic regulation of copper uptake in yeast via direct binding of $\mathrm{MAC} 1$ protein to upstream regulatory sequences of FRE1 and CTR1," Journal of Biological Chemistry, vol. 272, no. 28, pp. 17711-17718, 1997.

[56] A. J. Bird, S. Swierczek, W. Qiao, D. J. Eide, and D. R. Winge, "Zinc metalloregulation of the zinc finger pair domain," Journal of Biological Chemistry, vol. 281, no. 35, pp. 2532625335, 2006.

[57] E. B. Gralla, D. J. Thiele, P. Silar, and J. S. Valentine, "ACE1, a copper-dependent transcription factor, activates expression of the yeast copper, zinc superoxide dismutase gene," Proceedings of the National Academy of Sciences of the United States of America, vol. 88, no. 19, pp. 8558-8562, 1991.

[58] C. Gross, M. Kelleher, V. R. Iyer, P. O. Brown, and D. R. Winge, "Identification of the copper regulon in Saccharomyces cerevisiae by DNA microarrays," Journal of Biological Chemistry, vol. 275, no. 41, pp. 32310-32316, 2000.

[59] A. Selvaraj, K. Balamurugan, H. Yepiskoposyan et al., "Metal-responsive transcription factor (MTF-1) handles both extremes, copper load and copper starvation, by activating different genes," Genes and Development, vol. 19, no. 8, pp. 891-896, 2005.

[60] C. E. Ooi, E. Rabinovich, A. Dancis, J. S. Bonifacino, and R. D. Klausner, "Copper-dependent degradation of the
Saccharomyces cerevisiae plasma membrane copper transporter Ctrlp in the apparent absence of endocytosis," EMBO Journal, vol. 15, no. 14, pp. 3515-3523, 1996.

[61] B.-E. Kim, T. Nevitt, and D. J. Thiele, "Mechanisms for copper acquisition, distribution and regulation," Nature Chemical Biology, vol. 4, no. 3, pp. 176-185, 2008.

[62] M. J. Petris, K. Smith, J. Lee, and D. J. Thiele, "Copperstimulated endocytosis and degradation of the human copper transporter, hCtr1," Journal of Biological Chemistry, vol. 278, no. 11, pp. 9639-9646, 2003.

[63] I.-S. Song, H. H. W. Chen, I. Aiba et al., "Transcription factor Spl plays an important role in the regulation of copper homeostasis in mammalian cells," Molecular Pharmacology, vol. 74, no. 3, pp. 705-713, 2008.

[64] J. H. Freedman, M. R. Ciriolo, and J. Peisach, "The role of glutathione in copper metabolism and toxicity," Journal of Biological Chemistry, vol. 264, no. 10, pp. 5598-5605, 1989.

[65] E. D. Harris, "Cellular copper transport and metabolism," Annual Review of Nutrition, vol. 20, pp. 291-310, 2000.

[66] Y. Nose, B.-E. Kim, and D. J. Thiele, "Ctr1 drives intestinal copper absorption and is essential for growth, iron metabolism, and neonatal cardiac function," Cell Metabolism, vol. 4, no. 3, pp. 235-244, 2006.

[67] S. Ishida, F. McCormick, K. Smith-McCune, and D. Hanahan, "Enhancing tumor-specific uptake of the anticancer drug cisplatin with a copper chelator," Cancer Cells, vol. 17, no. 6, pp. 574-583, 2010. 